MIDAS

Museus e estudos interdisciplinares

$9 \mid 2018$

Varia

\title{
Ana Carvalho - Museus e Diversidade Cultural: Da Representação aos Públicos
}

Inês Lourenço

\section{(2) OpenEdition}

1 Journals

Edição electrónica

URL: http://journals.openedition.org/midas/1340

DOI: $10.4000 /$ midas. 1340

ISSN: 2182-9543

\section{Editora:}

Alice Semedo, Paulo Simões Rodrigues, Pedro Casaleiro, Raquel Henriques da Silva, Ana Carvalho

\section{Refêrencia eletrónica}

Inês Lourenço, "Ana Carvalho - Museus e Diversidade Cultural: Da Representação aos Públicos », MIDAS [Online], 9 | 2018, posto online no dia 25 janeiro 2018, consultado no dia 23 setembro 2020. URL : http://journals.openedition.org/midas/1340; DOI : https://doi.org/10.4000/midas.1340

Este documento foi criado de forma automática no dia 23 setembro 2020.

\section{(c) (i) (2)(2)}

Midas is licensed under a Creative Commons Attribution-NonCommercial-ShareAlike 3.0 International License 


\title{
Ana Carvalho - Museus e Diversidade Cultural: Da Representação aos Públicos
}

\author{
Inês Lourenço
}

\section{REFERÊNCIA}

Carvalho, Ana. 2016. Museus e Diversidade Cultural: Da Representação aos Públicos. Vol. 4.

Coleção Estudos de Museus. Casal de Cambra: Caleidoscópio e Direção-Geral de

Património Cultural. 311 páginas, ISBN: 9789896583927.

1 A obra em apreço, Museus e Diversidade Cultural: Da Representação aos Públicos (2016), resulta da investigação de doutoramento de Ana Carvalho e consiste numa abordagem inovadora no contexto da articulação entre museus e sociedade na contemporaneidade assente na mudança de paradigma, que torna os museus socialmente responsáveis, acessíveis, inclusivos e participativos.

2 Centrado nos desafios que os museus com coleções etnográficas enfrentam neste processo, este livro desenvolve amplamente a questão da relação entre esta nova abordagem museológica e o fenómeno da imigração, colocando a ênfase na relevância do papel dos museus na contemporaneidade.

3 Assim, reforçando a ideia de museus como «zonas de contacto» (p. 8) - uma noção citada a partir de James Clifford -, e como espaços caracterizados pela ambivalência, pela fragmentação e pela multivocalidade - ideias colhidas em autoras como Eilean Hooper-Grenhill e Marta Anico (p. 9) - Ana Carvalho propõe um olhar virado para as comunidades imigrantes e para a celebração da diversidade cultural, funcionando o museu como espaço de inclusão de novos patrimónios e detendo também crescentes responsabilidades.

4 O livro encontra-se bem estruturado, dividido em duas partes. A primeira, composta por dois capítulos, consiste no enquadramento teórico da obra, uma sistematização aprofundada, com vista à reflexão sobre o papel dos museus na contemporaneidade, especificamente no que respeita à sua interação com as comunidades imigrantes, quer 
enquanto novos públicos, quer enquanto agentes participativos nos processos de reinterpretação e de "construção de novas narrativas sobre identidades e património» (p. 18).

5 Partindo do pressuposto de que os museus poderão contribuir ativamente para uma «estratégia política e cultural para a promoção da diversidade cultural, envolvendo as populações imigrantes» (p. 20) a autora aborda três conceitos - multiculturalismo, interculturalidade e diversidade cultural - em articulação com o mundo dos museus, fazendo uma retrospetiva acerca da sua aplicabilidade, falhas e críticas. A autora demonstra como a interculturalidade como projeto político de transformação social como tal, não livre de tensões e de divergências - é uma alternativa ao modelo de multiculturalismo, no sentido em que aponta para um processo dinâmico em constante construção. Por conseguinte, a noção de diversidade cultural, assente nesta ideia de dinamismo e na possibilidade de inclusão, é apresentada pela autora como o ponto de partida para as políticas de atuação dos museus no que respeita ao que defende ser a dimensão social, ancorada em abordagens museológicas em conexão com a sociedade e na humanização dos museus, propondo a inclusão em contexto de museologia.

6 A abordagem proposta pela autora assenta na mudança de paradigma, através da qual as práticas museológicas valorizam o papel dos indivíduos, propondo, no caso da imigração, a ênfase na musealização do património dos imigrantes.

O foco do segundo capítulo são as coleções etnográficas, onde é feita uma contextualização histórica das coleções etnográficas na Europa, marcadas pelo passado colonial, propondo uma nova abordagem sobre estes objetos, à luz das sociedade contemporânea e em diálogo com a diversidade cultural. Como aponta a autora, o fim do colonialismo conduziu à redefinição, reinvenção e reformulação dos museus europeus. Esta mudança apresenta desafios, que são centrais na reflexão sobre as sociedades contemporâneas, sendo o momento pós-colonial propício à mudança da forma como se pensam as coleções e os objetos museológicos. A inclusão das perspetivas dos imigrantes (em muitos casos pertencentes às antigas colónias representadas nas coleções etnográficas) permite desafiar a noção de identidade nacional. Ana Carvalho demonstra, portanto, como através da adoção de estratégias de incorporação e de atualizações das coleções, é possível incentivar o diálogo com os imigrantes (que entes eram o "outro" representado nos museus), revelando «histórias escondidas» - citando autores como Wayne Modest e Helen Mears (p. 66) -, zonas de contacto, que proporcionam novas «histórias de contacto» - uma ideia colhida em Alice Semedo (p. 67).

O segundo capítulo explora ainda o potencial dos objetos, revelado na sua capacidade de emanar memórias e histórias e de serem veículos de autorrepresentação ou seja, «objetos sociais» (p. 68) - noção aplicada pela autora com base em Nina Simon - que permitem a inclusão de outras vozes e de narrativas criativas e, consequentemente, propiciadores do diálogo intercultural.

9 A segunda parte do livro consiste numa investigação exaustiva e é composta por quatro capítulos, três dos quais dedicados cada um a um museu específico, apresentando a sua contextualização histórica, seguida de uma análise centrada na problematização acerca das políticas no âmbito da diversidade cultural com vista à inclusão das populações migrantes. $O$ último capítulo, em jeito de síntese, sistematiza as principais conclusões deste estudo. 
10 Esta análise é feita com base em três estudos de caso constituídos por três museus europeus com coleções etnográficas: o Museum of World Culture, na Suécia, o World Museum of Liverpool, no Reino Unido e o Museu Nacional de Etnologia (MNE), em Portugal. Esta análise comparativa permitiu juntar reflexões a partir de museus que fossem representativos de uma diversidade de contextos e que em comum tivessem sido alvo de renovações nos últimos anos. Assim, foram abordadas as políticas de promoção da diversidade cultural negociadas por cada museu, particularmente no que respeita ao envolvimento com as comunidades imigrantes e a inclusão do seu património nas suas práticas museológicas. Esta análise comparativa permitiu também concluir que, apesar das especificidades históricas de cada museu, os três têm presente a consciência da alteração do seu papel em função das mudanças sociodemográficas das sociedades envolventes.

11 Esta pesquisa detalhada permitiu detetar o impacto de estratégias museológicas sobre comunidades imigrantes ao nível mais alargado da acessibilidade, mas também através de várias iniciativas (exposições, iniciativas e programação) na captação e envolvimento dos novos públicos e na inclusão dos contributos dessas mesmas comunidades, através das suas vozes e narrativas, fazendo destes não só consumidores, mas também produtores culturais. Assim, os três museus reconhecem, através das suas atividades, o potencial das coleções etnográficas para novas interpretações, assentes no envolvimento com as comunidades de imigrantes, revelando também a pertinência da temática central desta obra.

12 Na sua análise do Museum of World Culture, a autora enfatiza o trabalho de articulação das coleções etnográficas em colaboração com grupos de imigrantes através de técnicas participativas, demonstrando como o Património Cultural Imaterial (PCI) é um novo conceito operativo que permite incluir o enfoque nos grupos subrepresentados, como os imigrantes, incluindo «narrativas pessoais em torno da memória e da identidade numa perspetiva contemporânea e dinâmica [...] integradas na dinâmica expositiva» (pp. 113-114).

13 O World Museum of Liverpool é também um caso que permite refletir sobre a negociação do PCI (não tendo, contudo, o Reino Unido ratificado a Convenção da UNESCO para a Salvaguarda do Património Cultural Imaterial de 2003) e da sua compatibilidade com a adoção de uma perspetiva participativa, de intervenção social, descentralizadora do objeto e privilegiando a cultura da narrativa, ou seja, das ideias e histórias que emanam do objeto, associadas aos imigrantes e às suas comunidades. Estes exemplos pretendem demonstrar como uma estratégia para a diversidade cultural patente na prática museológica é facilitada pelo enfoque no PCI.

14 Finalmente, a abordagem centrada no MNE é aquela que permite à autora deixar mais pistas de reflexão e propostas de intervenção futura. A população imigrante em Portugal é um dos grupos excluídos no contexto dos públicos dos museus, e é neste sentido que são apresentados vários exemplos de iniciativas que colocaram em diálogo museus e imigrantes, quer no MNE, quer noutros museus portugueses, a partir dos quais são apresentadas propostas de trabalho futuro que permitam consolidar as várias experiências no âmbito da museologia participativa e na articulação entre museus e comunidades imigrantes em Portugal.

15 Assim, o principal passo será, segundo a autora, considerar o PCI como potenciador de «diálogo e respeito pelos patrimónios de diferentes grupos sociais» (p. 220). Sendo o MNE um espaço de representação da diversidade cultural, este poderá constituir uma 
oportunidade de «repensar narrativas nacionais face às múltiplas identidades e culturas» (p. 222) que a museologia participativa permite revelar. O MNE é apontado ao longo deste capítulo como capaz de contribuir favoravelmente para a estratégia de valorização da diversidade cultural, através da redefinição da sua missão e da sua política de atuação.

Importa ainda ressaltar a preocupação da autora em não usar acriticamente conceitos que podem ter interpretações problemáticas, como é o caso de identidades ou comunidades. Neste âmbito, a autora alerta para o risco de as instituições culturais manterem, no campo das suas iniciativas, estereótipos, promovendo olhares essencialistas e exóticos sobre o outro, ou seja, «cautela no ato de rotular o outro» (pp. $25,26)$, reproduzindo estereótipos acerca da cultura dos imigrantes.

17 A autora chama ainda a atenção para uma questão central ao abordar a temática da imigração: a necessidade de desconstrução da noção de comunidade, chamando a atenção para a multiplicidade de pertenças e de identidades dos imigrantes e alertando para o perigo de as práticas museológicas remeterem os imigrantes para categorias fechadas, para comunidades imaginadas. Consideramos, contudo, que este alerta devia ter um lugar de maior destaque, devendo surgir como problematização inicial em torno das comunidades, sendo este um conceito recorrente ao longo da obra.

Resumindo, Museus e Diversidade Cultural, é um contributo indispensável na análise da museologia contemporânea, oferecendo uma reflexão crítica das práticas museológicas no presente, e apontando pistas futuras para a definição de políticas públicas no âmbito da museologia, com vista à valorização do património dos imigrantes em Portugal.

\section{AUTORES}

\section{INÊS LOURENÇO}

Centro em Rede de Investigação em Antropologia (CRIA), ISCTE - Instituto Universitário de Lisboa), Portugal, ines.lourenco@iscte-iul.pt 